\title{
Linkages between Financial Sector CDS Spreads and Macroeconomic Influence in a Nonlinear Setting
}

\author{
Amine Lahiani*, Shawkat Hammoudeh ${ }^{* *}$ and Rangan Gupta ${ }^{* * *}$
}

\section{Highlights}

- The paper examines asymmetric and nonlinear transmissions for sector CDS spreads.

- The model is NARDL and CDSs are for bank, financial service and insurance sectors.

- The influences come from the financial, equity risk and energy price factors.

- There is evidence of short- and long-run nonlinearities and asymmetries for the CDSs.

- There are also short- and long-run asymmetries in the economic and risk influences.

\begin{abstract}
:
This paper investigates the asymmetric and nonlinear transmission of financial and energy prices to US five-year financial CDS sector index spreads for the banking, financial services and insurance sectors in the short- and long-run over the recent periods revolving around the global financial crisis. We employ the nonlinear ARDL (NARDL) model to account for the short- and long-run asymmetries in the sensitivity of those CDS sector index spreads to their determinants. Our findings suggest that there is evidence of short- and long-run nonlinearities and asymmetries in the adjustment process of the three CDS variables. There are also shortand long-run asymmetries in the influences of macroeconomic and financial variables on the CDS sector spreads. These findings are important for policymakers who deal with credit risks at the sector levels.JEL Codes: C32, F65, G01
\end{abstract}

Keywords: Sector CDS, Financial crisis, Asymmetric adjustments, NARDL model

\footnotetext{
LEO-Laboratoire d'Economie d'Orléans, University of Orléans - France. Email : amine.lahiani@univorleans.fr.

** Corresponding author. LeBow College of Business, Drexel University, Philadelphia, United States. Email: hammousm@drexel.edu.

*** Department of Economics, University of Pretoria, Pretoria, 0002, South Africa. Email : rangan.gupta@up.ac.za.
} 


\section{Introduction}

Many scholars, financial analysts and policymakers hold the financial institutions and government regulators responsible for issuing or allowing too many credit derivatives that generated too much risk in many global economies. The most important part of the credit derivatives are the credit default swaps (CDSs), which have become complicated assets that spread risks around the world's financial sectors instead of serving as hedging instruments. A CDS index is a highly liquid, standardized credit security that trades at a very small bid-ask spread. CDSs can be efficient in processing information on evolving risks in the financial sectors and the rest of the economy (see Norden \& Weber, 2004; and Greatrex, 2008 among others). The magnitude of the financial credit spreads gauges the default risk exposure of the institutions that make up the financial sectors. A widening in a CDS spread in response to certain credit events indicates an increase in the level of credit risk in the pertinent financial/economic sector, while a narrowing in the spread reveals a decrease in the credit risk. Moreover, in bad times the risk in the CDS markets can be exponential and in this case the strategy that the premium covers the risk does not work.

During the recent global financial crisis (GFC) the risk initially transmitted from the financial institutions such as AIG to the real sector firms such as GM, followed by counter risk transmission. The problem affected the derivative markets, corporate bond markets and money markets. Given the roles played by the financial institutions and the consequences of the recent GFC, this paper is motivated to examine the dynamic behavior of the CDS spread sector indices for the banking, financial services and insurance sectors as well as the comportment of other measures of risk that are related to those financial spreads in the preand post-periods of the GFC.

Financial CDS sector indices may be influenced differently by shocks and credit events due to differences in the investment space of banks, financial services companies and 
insurance companies that make up the financial sectors. Banks receive deposits and specialize in making loans, while financial services companies are not depository institutions and invest in more risky credit assets such as low grade investments and high yield corporate bonds. Insurance companies focus more on less-risky fixed income investments, and thus are more conservative than banks and financial services institutions. They also sell CDS protection contracts as well as they buy them. They issue bonds and also insure the investors who buy them, thus they may have double CDS risk in the case of defaults. Therefore, one sector may react more or less than other sectors to credit events that may affect their own sectors as well as the overall economy. Banks may react less to a business bankruptcy or a financial regulation than other financial institutions. There are several pressures within the financial sectors that lead to different risk reactions. There are pressures related to liquidity which should have differential impacts on the financial sectors' CDS indices. There are also pressures related to inflation expectation and market risks.

The purpose of this paper is to investigate the long- and short-run linkages between the sector CDS index spread dynamics for CDS_Banks, CDS_Financial service and CDS_Insurance in a nonlinear setting that includes a set of explanatory macroeconomic and financial variables namely the 3-month Libor, the federal funds rate, the Treasury bill rate, VIX and WTI. These variables reflect risks in the money, credit and oil markets. In particular, several banks have large exposures to Libor through their interest rate derivative portfolios and have recently profited from the rapid descent of this rate. Insurance companies are not involved in borrowing unsecured funds from other banks, but they may benefit from higher LIBOR as the pricing of loans that reflects the risk-free rate and the CDS spread. Moreover, the federal funds rate can be regarded as the marginal cost of borrowing, and therefore other rates are set according to it. The changes in oil prices also raise uncertainty in the financial markets, and that is reflected in the CDS markets. There is also a theoretical relationship 
between credit default swap spreads and bond yield spreads. This relationship holds fairly well and can be used to estimate the benchmark five-year risk-free rate used by participants in the credit default swap market (Hull et al., 2004 and Snider and Youle, 2009).

To achieve this purpose, we employ the recently developed approach — the Nonlinear Autoregressive Distributed Lags (NARDL) model that allows one to test for long- and shortrun asymmetries. Moreover, unlike the standard cointegration techniques (Johansen and Engle-Granger), this model permits one to test for hidden cointegration and use time series that have different orders of integration (i.e., I(1) and I(0)). The computation of asymmetric dynamic multipliers allows one to quantify the respective responses of the sector CDS spreads to positive and negative changes in each of the explanatory variables through estimating the positive and negative partial sum decompositions of these variables.

Therefore, this article contributes to the existing literature by addressing nonlinearity and asymmetry in modeling the time-variations in the financial CDS sector index spreads, taking into account the recent GFC, as well as the influence of economic and financial variables. In contrast to the existing literature on CDS sector indices, this study employs the NARDL model which has all the benefits and advantages described above. Specifically, an important advantage of the NARDL model is that it can combine $\mathrm{I}(0)$ and $\mathrm{I}(1)$ variables, making the 'bounds test' appropriate to assess the presence of long-run relationships between the variables under consideration (Banerjee et al., 1998 and Pesaran et al., 2001). This approach also allows for computing in a simple manner the responses of CDS sector spreads to a shock in each of the control variables we use. The zero threshold allows assessing accurately the impact of a positive and negative shocks to the control variables on the CDS spreads. Thus, this nonlinear model offers a more general framework than the linear counterpart because it accounts simultaneously for several stylized patterns of financial series including nonlinearity in the short-run, nonlinearity in the long-run and common movements. Including all of these 
patterns in a unique model is very helpful to analyze the links between the financial time series and their forcing factors, without omitting any relationships that may be defined by an unknown, true data generating process DGP. The study also includes risks in the equity market among the macroeconomic influences on the CDS sector index spreads.

In compassion with the existing literature, we use a novel methodology which accounts for several statistical stylized facts that are largely ignored by previous studies. For instance, Hammoudeh and Sari (2011) employ the linear ARDL model, while our study utilizes the nonlinear ARDL (NARDL) model which is more advantageous than its linear counterpart since it is well known in the literature that financial time series are nonlinear. Asymmetry and structural breaks (e.g., major credit events, bankruptcy) are forms of nonlinearities and are related to the CDS series (Galil, Shapir, Amiram, \& Ben-Zion, 2014). Additionally, Hammoudeh, Bhar and Liu (2013) and Hammoudeh, Nandha et al. (2013)use the linear vector error correction model which rules out asymmetries and structural breaks. Both Hammoudeh and Sari (2011) and Hammoudeh, Bhar et al. (2013) and Hammoudeh, Nandha et al. (2013) also use a sample period that ends in 2009 which does not account for the effects of the most recent financial crises, while ours ends in May 2014. Moreover, Annaert, De Ceuster, Van Roy, and Vespro (2013) use multivariate panel rolling regressions to account for the timevarying effects of the risk free rate, leverage, equity volatility, bid-ask spread, term structure slope, swap spread, corporate bond spread, market return and market volatility on the changes in the CDS spreads for 32 Euro-area banks. Differently, we consider the sector CDS index spreads of three indices namely banking, financial and insurance sectors.

This paper is organized as follows. Section 2 provides a review of the related literature. Section 3 presents the methodology and data description. Section 4 discusses the empirical results. Section 5 concludes with a discussion of the limitations of our empirical methodology and provides some possible extensions. 


\section{Related literature}

A number of studies have investigated the dynamic movements in credit default spreads (e.g., Longstaff et al., 2005, Berndt et al., 2008, Raunig and Scheicher, 2009, Zhang et al., 2009, Hammoudeh et al., 2013 and Hammoudeh et al., 2013). For example, Hammoudeh, Nandha and Yuan (2013) examine the movements of the CDS indices for the three financial-sectors, banking, financial services and insurance in the short- and long-run over the period 2004-2009 and find that the individual dynamic adjustments to the equilibrium are different for those sectors. Other studies examine the CDS spreads as pure measures of credit risk (e.g., Bharath and Shumway, 2008, Blanco et al., 2005, Ericsson et al., 2006 and Ericsson et al., 2009) or analyze the relationships between equity, bond and credit markets using time series instead of cross-sectional data (e.g., Bystrom, 2006, Zhu, 2006, Fung et al., 2008, Forte and Lovreta, 2009, Norden and Weber, 2009 and Srivastava et al., 2016). For example, Berndt et al. (2008) investigate the variations in the risk premium that comprises a major component of the CDS spreads for the US corporate debt in three sectors: broadcasting and entertainment, health care, and oil and gas for the period 2000-2004. The authors find remarkable variations in the risk premium in those sectors over the period 20022003. Blanco et al. (2005), using a small sample of US and European firms, find support for the theoretical arbitrage relationship between CDS prices and credit spreads on average. When this relationship is violated, the CDS index spread can be considered as the upper bound for the true credit risk price, while the credit spread can be viewed as the lower bound. The results thus suggest that the CDS is the main forum for credit risk price discovery. More recently, Srivastava et al. (2016) find that the recent financial crisis that global shocks first affect the S\&P option market and then spill over to the sovereign CDS market.

Bystrom (2006) investigates the properties of the Dow Jones iTraxx index which is an index of CDS securities on 12 European reference entities. This author finds that CDS spreads 
are significantly auto-correlated in the seven sectors comprising the iTraxx index, and also are significantly negatively related to the contemporaneous stock returns in all sectors except energy, consumers, and financials. Norden and Weber (2009) examine the monthly, weekly and daily lead-lag relationships between CDS, bond and stock markets, using autoregressive and vector error-correction models over the period 2000-2002. They find that stock returns lead the changes in CDS and bond spreads, and that changes in CDS spreads Granger-cause changes in bond spreads for a higher number of firms than the other way around. These results suggest that the CDS market is more sensitive to the stock market than the bond market, and that this sensitivity increases for the lower credit quality. In addition, the CDS market contributes more to price discovery than the bond market and this result is stronger for the US than for European firms.

Stanton and Wallace (2011) examine the relevance of the ABX.HE indices, which track the CDSs on the US sub-prime residential mortgage-backed securities (RMBS) to the mortgage default rates during the financial crisis. Their results cast doubts on the suitability of the prices of the AAA ABX.HE index CDS as valuation benchmarks. Using a large sample of firms with both CDS and options data, Cao, Yu, and Zhong (2010) find that individual firms' implied volatility dominates historical volatility in explaining the time-series variations in CDS spreads. Che and Kapadia (2012) suggest that the VIX play a role consistent with its role as a "fear index" in explaining credit spreads. Blau and Roseman (2014) examine the CDS spreads for nearly all European countries around August 5, 2011 which witnessed a downgrade in the US sovereign credit ratings. The authors show that the European countries that have the smallest GDP per capita have not recently been downgraded and use the Euro have the largest increases in CDS spreads.

Some recent studies also recognize that the dynamics of CDS spreads may be nonlinear, asymmetric and exposed to regime shifts due to frequent turbulences and extreme 
market conditions. In this regard, Hammoudeh, Bhar et al. (2013) and Hammoudeh, Nandha et al. (2013) focus on the relationships between financial sector CDS spreads (banking, financial services and insurance) before, during and after the 2008/2009 global financial crisis, while controlling for other measures of risks such as TED, ${ }^{1}$ inflation expectations and corporate risk spread. Chen, Hammoudeh, and Yuan (2011) examine the asymmetric adjustments to the long-run equilibrium for the same sector CDS spreads in the presence of a threshold effect. Methodologically, Hammoudeh and Sari (2011) employ the linear (symmetric) Autoregressive Distributed Lags (ARDL) model to uncover the relationship between the financial CDS spread indices of the banking, financial services and insurance sectors and short- and long-term Treasury securities and the S\&P 500 index. However, those authors do no account for other measures of financial stress and credit risks such as the default risk spreads and the expected volatility risk.

\section{Methodology and data}

\subsection{The empirical model}

The previous literature related to the CDS spreads has so far provided mixed results regarding the short- and long-run links between the CDS spreads and their financial and economic determinants. For instance, Game and $\mathrm{Wu}$ (2013) find strong evidence of cointegration between CDS spreads and corporate bond spreads of a panel of US firms during the 2007-2009 financial crisis. Their conclusion is obtained by employing an improved power residual-based test. However, the Johansen cointegration test finds little evidence of cointegration between the CDS spreads and financial data. Indeed, Chan-Lau and Kim (2004) provide mixed results regarding cointegration between CDS, bond and equity markets. The above findings could be due to the inadequacy between the selection of a given methodology and the true Data Generating Process (DGP). In fact, it is argued that results of the Johansen cointegration test are sensitive to the structure of residuals (Hansen, 1992). Also, it is 
misleading to test for linear cointegration while the true cointegrating system behaves in a nonlinear manner (Nesmith and Jones, 2008). Moreover, standard cointegration tests do not capture the possible hidden cointegration between the time series under consideration. Hidden cointegration arises when CDS spreads may have relationships with only certain components of their determinants, such as the 3-month Libor, the federal funds rate, the 3-month Treasury bill rate, the S\&P equity index implied volatility (VIX) and the 3-month Western Texas Intermediate (WTI) crude oil futures contracts (Granger and Yoon, 2002).

The recent literature on cointegration has introduced a novel and more flexible methodology that allows for simultaneously accounting for unobserved cointegration, and short- and long-run cointegration. This methodology is based on the use of the extended ARDL model that accounts for asymmetry in the short- and long-run (Phillips and Hansen, 1991; Pesaran, Smith and Shin, 1996). The most general NARDL model with short- and long-run asymmetries can be written as follows:

$$
\begin{aligned}
& \Delta C D S_{j}=\mu+\rho C D S_{j_{t-1}}+\theta_{\text {libor }}^{+} \text {libor }_{t-1}^{+}+\theta_{\text {libor }}^{-} \text {libor }_{t-1}^{-}+\theta_{f f r}^{+} \text {ffr }_{t-1}^{+}+\theta_{f f r}^{-} \text {ffr }_{t-1}^{-}+ \\
& \theta_{T B}^{+} T B_{t-1}^{+}+\theta_{T B}^{-} T B_{t-1}^{-}+\theta_{v i x}^{+} v i x_{t-1}^{+}+\theta_{v i x}^{-} v i x_{t-1}^{-}+\theta_{w t i}^{+} w t i_{t-1}^{+}+\theta_{w t i}^{-} w t i_{t-1}^{-}+ \\
& \sum_{i=1}^{p-1} \alpha_{i} \Delta \text { CDSj }_{t-i}+\sum_{i=0}^{q-1}\left(w_{i, l i b o r}^{+} \Delta \text { libor }_{t-i}^{+}+w_{i, l i b o r}^{-} \Delta l i b o r_{t-i}^{-}\right)+\sum_{i=0}^{q-1}\left(w_{i, f f r}^{+} \Delta \text { fr }_{t-i}^{+}+\right. \\
& \left.w_{i, f f r}^{-} \Delta f f r_{t-i}^{-}\right)+\sum_{i=0}^{q-1}\left(w_{i, T B}^{+} \Delta T B_{t-i}^{+}+w_{i, T B}^{-} \Delta T B_{t-i}^{-}\right)+ \\
& \sum_{i=0}^{q-1}\left(w_{i, v i x} \Delta v i x_{t-i}^{+}+w_{i, v i x}^{-} \Delta v i x_{t-i}^{-}\right)+\sum_{i=0}^{q-1}\left(w_{i, w t i}^{+} \Delta w t i_{t-i}^{+}+w_{i, w t i}^{-} \Delta w t i_{t-i}^{-}\right)
\end{aligned}
$$

where $j$ stands for ban, fin and ins, $p=2$ for CDS_ban, CDS_fin and CDS_ins, $q=6$ for CDS_ban and 5 for CDS_fin and CDS_ins.

\subsection{Data description}

Our dataset consists of monthly five-year CDS sector index spreads for the three financial sectors banks, financial services and insurance sectors of the US economy. We consider the time series of these sector CDS indices as the response variables. As for the shock variables, 
we collected the data for the 3-month Libor (libor), the 3-month Treasury bill rate $(t b)$, the federal funds rate $(f f r)$, the S\&P equity index implied volatility index (VIX) and the 3-month WTI crude oil futures price. Data is collected from DataStream and covers the period of January, 2004 to May, 2014. Investors track the CDS represented in the CDX/VIX ratio to foresee credit crises and possible crashes in the stock markets. Table 1 provides the summary statistics of the CDS and control variables used in this study, Fig. 1 plots the evolution of those variables over time.

Table 1. Summary Statistics of Variables used in Estimation

\begin{tabular}{|c|c|c|c|c|c|c|c|c|}
\hline Variables & Observation & Mean & SD & Max & Min & Skewness & Kurtosis & JB test stat \\
\hline CDS_ban & 125 & 4.2152 & 0.9796 & 5.9052 & 2.3434 & -0.3613 & 1.7668 & $\begin{array}{c}10.64047 \\
(0.0049)\end{array}$ \\
\hline CDS_fin & 125 & 5.0216 & 1.2296 & 7.2418 & 3.0879 & -0.1155 & 1.6632 & $\begin{array}{c}9.585914 \\
(0.0083)\end{array}$ \\
\hline CDS_ins & 125 & 5.0822 & 1.2882 & 7.6298 & 2.8625 & -0.0419 & 1.7475 & $\begin{array}{c}8.207477 \\
(0.0165)\end{array}$ \\
\hline ffr & 125 & 1.6590 & 1.9481 & 5.3300 & 0.0400 & 0.8476 & 2.1100 & $\begin{array}{c}19.09389 \\
(0.0001)\end{array}$ \\
\hline libor & 125 & 2.1242 & 1.8535 & 5.5800 & 0.2491 & 0.7330 & 1.9598 & $\begin{array}{c}16.82948 \\
(0.0002)\end{array}$ \\
\hline tb & 125 & 1.5298 & 1.8495 & 5.1500 & 0.0100 & 0.8752 & 2.1749 & $\begin{array}{c}19.50485 \\
(0.0001)\end{array}$ \\
\hline VIX & 125 & 2.9175 & 0.3814 & 4.2270 & 2.3331 & 1.0319 & 3.8156 & $\begin{array}{c}25.64938 \\
(0.0000)\end{array}$ \\
\hline WTI & 125 & 4.3024 & 0.3172 & 4.9492 & 3.5178 & -0.6170 & 2.6928 & $\begin{array}{c}8.421159 \\
(0.0148)\end{array}$ \\
\hline
\end{tabular}

Note: Variables are as defined in text; J-B is the Jarque-Bera test of normality with $p$-values in parentheses

Fig. 1 plots the evolution of the three sector CDS indices and the economic and energy control variables over the sample period as shown below. 


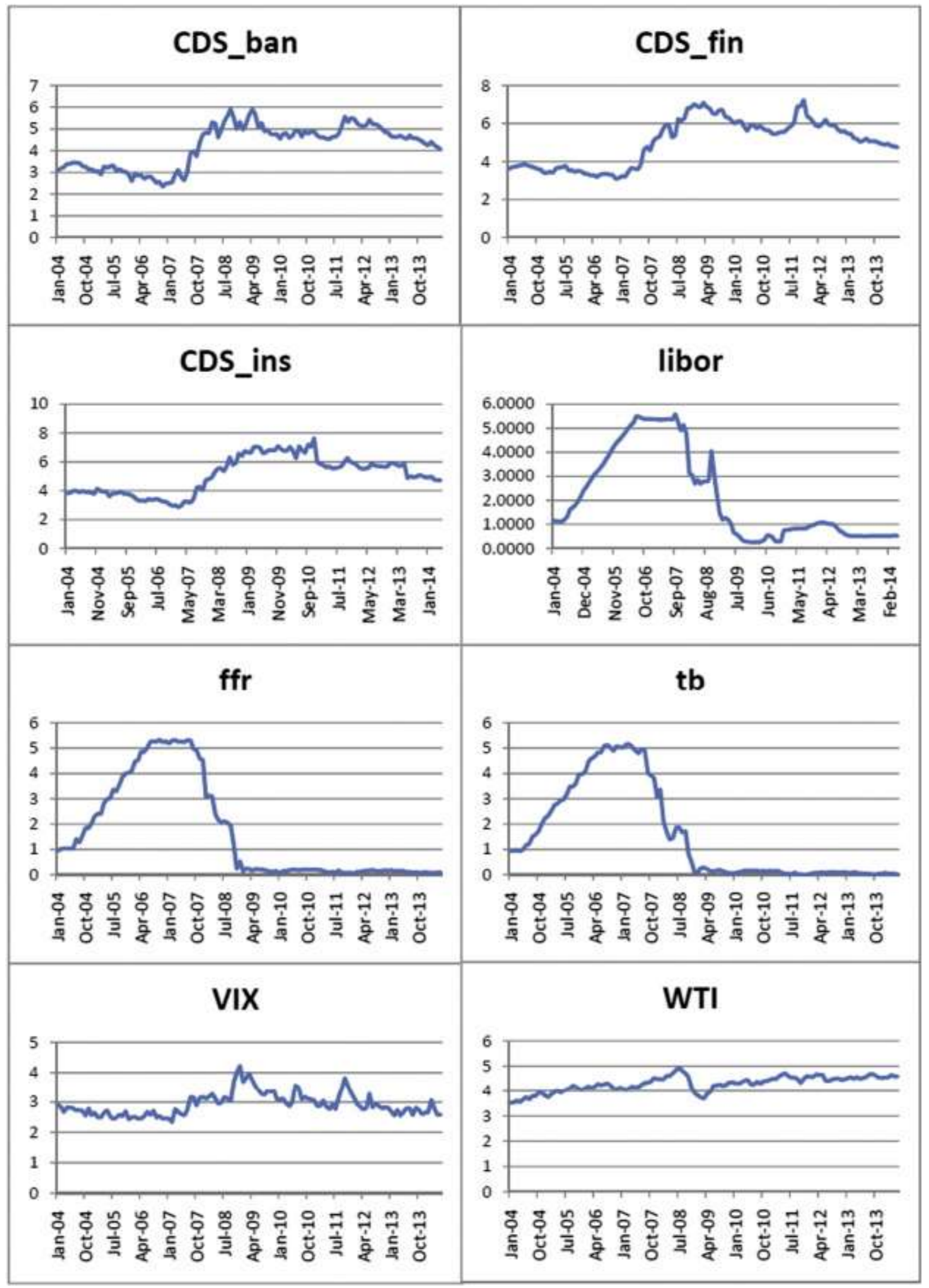

Fig. 1. Evolution of CDS indices and control variables. 


\subsubsection{Response variables}

The monthly time series of the sector CDS index spreads for the three sectors cover the period from January 2004 to May 2014, totalizing 125 observations. This period is chosen because it includes several crises which may induce a significant nonlinearity in the short- and long-run adjustments of the CDS spreads since the CDSs are highly liquid and used to hedge against credit risk in the credit derivatives market. In addition, the CDS's in the considered period have moved from protection to speculation as sellers and buyers of those CDS's were no longer owners of the underlying credit asset (loan or bond), but were just betting on the possibility of a "credit event" of a specific asset such as bankruptcy, restructuring or default (Zabel, 2008).

\subsubsection{Shock variables}

We consider five control variables (Libor, tb, ffr, VIX and WTI). It is well known that when the inter-bank market is more liquid than the CDS market the CDS spread will be larger to price this illiquidity. Changes in the federal funds rate are shown to impact significantly sovereign CDS's which in turn affect the sector CDS spreads. In addition, CDS spreads react to communications regarding the federal funds rate by members of the US Federal Open Market Committee (FOMC). For example, Fender et al. (2012) consider a sample of emerging markets and find no evidence of CDS reaction to European Central Bank's (ECB) and US interest rates before the world financial crisis (before July 2007). In contrast, this finding does not hold anymore during the crisis period going from August 2007 to December 2011, reflecting the care of investors about the new international market conditions.

VIX is considered as a proxy for the country's macroeconomic risk which is found to explain significantly changes in credit default swap spread after controlling for macroeconomic variables and firm-specific covariates (Che and Kapadia, 2012). The oil price 
is shown to have an important impact on economic and financial variables either through direct or indirect channels. In particular, Arouri et al. (2014) argue that the oil price - among the other control variables the federal funds rate, VIX, the oil price and TED - has the most pronounced nonlinear effect on the CDS spreads in the banking-insurance sector.

\section{Empirical results}

\subsection{Estimation results}

Table 2 reports the Wald statistics and their corresponding p-values for the test that checks for the long- (WLR) and short-run (WSR) symmetries in the NARDL model which is provided in Eq. (1). The results indicate that in the long-run the federal funds rate and the Treasury bill rate affect the three sector CDS indices in an asymmetric and nonlinear manner, while the 3-month Libor, VIX and WTI have linear symmetric impacts on those indices. It is worth mentioning that there is a close positive correlation between VIX and CDS as both track risks in their own markets. If the default risk of a company increases, its stock price is likely to fall and its put option volatility is likely to rise. Oil prices have a positive relations with the CDS's of oil sensitive corporations such as the airlines while they have a negative relation with CDS's of energy companies.

Overall, those results show that the U.S. monetary policy and the government $\mathrm{T}$ bill rate have a more lasting effect on the U.S. CDS indices than the market rate Libor the, U.S. oil price and the U.S. volatility index. There are investors who price bond risk in with movement in CDS spreads in analogue to those who price in equity risk with VIX. Moreover, Cao et al. (2010) show that the volatility risk premium embedded in option prices covaries with the CDS spread. Galil et al. (2014) show that change in VIX has a significant explanatory power of changes in CDS spreads in the absence of market factors. 
In the short-run, the federal funds rate and the Treasury bill rate affect asymmetrically the sector CDS index spreads. This asymmetric impact is more pronounced on the CDS_Banks and the CDS_Insurance (significant at the 5\% level) than on the CDS_Financial Service (significant at the $10 \%$ level). In addition, VIX shows an asymmetric short-run impact on the price dynamics of the CDS_Insurance.

Table 2: Long-run and short-run asymmetry tests

\begin{tabular}{|c|c|c|}
\hline & $\mathrm{W}_{\mathrm{LR}}$ & $\mathrm{W}_{\mathrm{SR}}$ \\
\hline \multicolumn{3}{|c|}{ CDS_ban } \\
\hline libor & $1.593[0.213]$ & $0.083[0.774]$ \\
\hline ffr & $4.776 * *[0.034]$ & $6.684 * *[0.013]$ \\
\hline $\mathrm{tb}$ & $5.075 * *[0.029]$ & $5.221 * *[0.027]$ \\
\hline vix & $2.070[0.157]$ & $1.466[0.232]$ \\
\hline wti & $1.823[0.184]$ & $1.015[0.319]$ \\
\hline \multicolumn{3}{|c|}{ CDS_fin } \\
\hline libor & $2.452[0.123]$ & 1.504 [0.225] \\
\hline ffr & $4.355 * *[0.041]$ & $3.461 *[0.068]$ \\
\hline tb & $5.877 * *[0.019]$ & $3.674 *[0.060]$ \\
\hline vix & 0.014 [0.905] & $1.137[0.291]$ \\
\hline wti & 0.280 [0.599] & $1.035[0.313]$ \\
\hline \multicolumn{3}{|c|}{ CDS_ins } \\
\hline libor & $0.786[0.379]$ & $0.098[0.755]$ \\
\hline ffr & $3.242 *[0.077]$ & 7.180 ** [0.010] \\
\hline tb & $5.055 * *[0.028]$ & $7.287 * * *[0.007]$ \\
\hline vix & $0.118[0.732]$ & $3.709 *[0.059]$ \\
\hline wti & $0.293[0.590]$ & $0.064[0.800]$ \\
\hline
\end{tabular}

Notes: $W_{S R}$ and $W_{L R}$ refer to the Wald statistics for the short- and long-run symmetry null hypotheses. The asterisks $* * *, * *$ and $*$ indicate rejection of the null of symmetry at the $1 \%, 5 \%$ and $10 \%$ respectively.

The results in Table 2 allows defining for each sector CDS index a restricted NARDL model in which long- and short-run symmetries are imposed based on the significance of the results of the Wald testl. The following NARDL models are then estimated for the respective sector CDS indices CDS_ban, CDS_fin and CDS_ins: 


$$
\begin{aligned}
& \Delta C D S_{-} \text {ban }_{t}=\mu+\rho C D S_{-} \text {ban }_{t-1}+\theta_{\text {libor }} \text { libor }_{t-1}+\theta_{f f r}^{+} \text {ff }_{t-1}^{+}+\theta_{f f r}^{-} \text {ffr }_{t-1}^{-}+ \\
& \theta_{T B}^{+} T B_{t-1}^{+}+\theta_{T B}^{-} T B_{t-1}^{-}+\theta_{\text {vix }} \text { vix }_{t-1}+\theta_{w t i} \text { wti }_{t-1}+\alpha_{1} \Delta \text { CDS_ban }_{t-1}+ \\
& \sum_{i=0}^{5} w_{i, l i b o r} \Delta l i b o r_{t-i}+\sum_{i=0}^{5}\left(w_{i, f f r}^{+} \Delta f f r_{t-i}^{+}+w_{i, f f r}^{-} \Delta f f r_{t-i}^{-}\right)+\sum_{i=0}^{5}\left(w_{i, T B}^{+} \Delta T B_{t-i}^{+}+\right. \\
& \left.w_{i, T B}^{-} \Delta T B_{t-i}^{-}\right)+\sum_{i=0}^{5} w_{i, v i x} \Delta v i x_{t-i}+\sum_{i=0}^{5} w_{i, w t i} \Delta w t i_{t-i}
\end{aligned}
$$

$$
\begin{aligned}
& \Delta C D S_{-} \text {fin }_{t}=\mu+\rho C D S_{-} \text {fin }_{t-1}+\theta_{\text {libor }} \text { libor }_{t-1}+\theta_{f f r}^{+} \text {ffr }_{t-1}^{+}+\theta_{f f r}^{-} \text {ffr }_{t-1}^{-}+\theta_{T B}^{+} T B_{t-1}^{+}+ \\
& \theta_{T B}^{-} T B_{t-1}^{-}+\theta_{\text {vix }} \text { vix }_{t-1}+\theta_{w t i} \text { wti } i_{t-1}+\alpha_{1} \Delta C D S_{-} \text {fin }_{t-1}+\sum_{i=0}^{4} w_{i, l i b o r} \Delta l i b o r_{t-i}+ \\
& \sum_{i=0}^{4}\left(w_{i, f f r}^{+} \Delta f f r_{t-i}^{+}+w_{i, f f r}^{-} \Delta f f r_{t-i}^{-}\right)+\sum_{i=0}^{4}\left(w_{i, T B}^{+} \Delta T B_{t-i}^{+}+w_{i, T B}^{-} \Delta T B_{t-i}^{-}\right)+ \\
& \sum_{i=0}^{4} w_{i, v i x} \Delta v i x_{t-i}+\sum_{i=0}^{4} w_{i, w t i} \Delta w t i_{t-i}
\end{aligned}
$$

$$
\begin{aligned}
& \Delta C D S_{-} \text {ins }_{t}=\mu+\rho C D S_{-} \text {ins }_{t-1}+\theta_{\text {libor }} \text { libor }_{t-1}+\theta_{f f r}^{+} \text {ffr }_{t-1}^{+}+\theta_{f f r}^{-} \text {ffr }_{t-1}^{-}+\theta_{T B}^{+} T B_{t-1}^{+}+ \\
& \theta_{T B}^{-} T B_{t-1}^{-}+\theta_{v i x} \text { vix }_{t-1}+\theta_{w t i} w_{t i} i_{t-1}+\alpha_{1} \Delta C D S_{-} i n s_{t-1}+\sum_{i=0}^{4} w_{i, l i b o r} \Delta l i b o r_{t-i}+ \\
& \sum_{i=0}^{4}\left(w_{i, f f r}^{+} \Delta f f r_{t-i}^{+}+w_{i, f f r}^{-} \Delta f f r_{t-i}^{-}\right)+\sum_{i=0}^{4}\left(w_{i, T B}^{+} \Delta T B_{t-i}^{+}+w_{i, T B}^{-} \Delta T B_{t-i}^{-}\right)+ \\
& \sum_{i=0}^{4}\left(w_{i, v i x}^{+} \Delta v i x_{t-i}^{+}+w_{i_{i}, v i x}^{-} \Delta v i x_{t-i}^{-}\right)+\sum_{i=0}^{4} w_{i, w t i} \Delta w t i_{t-i}
\end{aligned}
$$

The results in Table 3 indicate that overall the estimated NARDL models are stable as the coefficient related to the lagged CDS sector spreads is negative and statistically significant in all cases. ${ }^{3}$ The 3-month Libor has no long-run effects on the CDS_Banks, while it has a highly significant long-run effect on the CDS_Insurance and a weakly significant long-run effect on the CDS_Financial service. There is suggestive evidence that many banks have large exposures to the Libor through their interest rate derivative portfolios and have recently profited from the rapid descent of Libor (Snider \& Youle, 2009). There are \$350 trillion of swaps that are indexed by the Libor. On the other hand, insurance companies are not involved in borrowing unsecured funds from other banks. They may benefited from higher LIBOR as pricing of loans reflects the risk free rate and the CDS spread. 
Table 3: Estimation results of the NARDL CDS models

\begin{tabular}{|c|c|c|c|c|c|}
\hline & CDS_ban & & CDS_fin & & CDS_ins \\
\hline CDS_bant-1 & $\begin{array}{c}-0.317 * * * \\
(0.113)\end{array}$ & CDS_fint-1 & $\begin{array}{c}-0.254 * * * \\
(0.087)\end{array}$ & CDS_ins $s_{t-1}$ & $\begin{array}{c}-0.351 * * * \\
(0.097)\end{array}$ \\
\hline libor $_{t-1}$ & $\begin{array}{c}0.100 \\
(0.395)\end{array}$ & libor $_{t-1}$ & $\begin{array}{l}0.167 * \\
(0.086)\end{array}$ & libor $_{t-1}$ & $\begin{array}{c}-0.634 * * * \\
(0.200)\end{array}$ \\
\hline$f f r_{t-1}^{+}$ & $\begin{array}{c}0.850 \\
(0.589)\end{array}$ & $f f r_{t-1}^{+}$ & $\begin{array}{l}-0.460 \\
(0.429)\end{array}$ & $f f r_{t-1}^{+}$ & $\begin{array}{l}-0.604 \\
(0.685)\end{array}$ \\
\hline$f f r_{t-1}^{-}$ & $\begin{array}{c}1.993 * * * \\
(0.551) \\
\end{array}$ & $f f r_{t-1}^{-}$ & $\begin{array}{c}0.800^{* * *} \\
(0.380) \\
\end{array}$ & $f f r_{t-1}^{-}$ & $\begin{array}{l}1.636^{* *} \\
(0.662) \\
\end{array}$ \\
\hline$T B_{t-1}^{+}$ & $\begin{array}{l}-0.988 \\
(0.660)\end{array}$ & $T B_{t-1}^{+}$ & $\begin{array}{c}0.356 \\
(0.467)\end{array}$ & $T B_{t-1}^{+}$ & $\begin{array}{l}1.297 * \\
(0.768)\end{array}$ \\
\hline$T B_{t-1}^{-}$ & $\begin{array}{c}-2.124 * * * \\
(0.615)\end{array}$ & $T B_{t-1}^{-}$ & $\begin{array}{c}-0897 * * \\
(0.401)\end{array}$ & $T B_{t-1}^{-}$ & $\begin{array}{l}-0.908 \\
(0.657)\end{array}$ \\
\hline$v^{i} x_{t-1}$ & $\begin{array}{c}0.343 * * \\
(0.181) \\
\end{array}$ & $\operatorname{vix}_{t-1}$ & $\begin{array}{l}0.423 * \\
(0.214) \\
\end{array}$ & $v^{2 i x_{t-1}}$ & $\begin{array}{c}0.873 * * * \\
(0.307) \\
\end{array}$ \\
\hline$w t i_{t-1}$ & $\begin{array}{c}0.016 \\
(0.350) \\
\end{array}$ & $w t i_{t-1}$ & $\begin{array}{c}0.049 \\
(0.284) \\
\end{array}$ & $w t i_{t-1}$ & $\begin{array}{c}0.343 \\
(0.440) \\
\end{array}$ \\
\hline$\Delta C D S \_b a n_{t-1}$ & $\begin{array}{l}-0.018 \\
(0.130)\end{array}$ & $\Delta C D S_{-} f_{i n} n_{t-1}$ & $\begin{array}{l}-0.094 \\
(0.110)\end{array}$ & $\Delta C D S_{-}$ins $_{t-1}$ & $\begin{array}{l}-0.186^{*} \\
(0.108)\end{array}$ \\
\hline$\Delta l i b o r_{t}$ & $\begin{array}{c}-0.404 * * \\
(0.167)\end{array}$ & $\Delta$ libor $_{t-3}$ & $\begin{array}{c}-0.256^{* *} \\
(0.124)\end{array}$ & $\Delta l i b o r_{t}$ & $\begin{array}{c}-0.593 * * \\
(0.237)\end{array}$ \\
\hline$\Delta$ libor $_{t-1}$ & $\begin{array}{l}-0.312^{*} \\
(0.185)\end{array}$ & $\Delta f f r_{t-3}^{+}$ & $\begin{array}{l}0.556^{*} \\
(0.292)\end{array}$ & $\Delta f f r_{t}^{+}$ & $\begin{array}{c}0.963 * * \\
(0.427)\end{array}$ \\
\hline$\Delta l i b o r_{t-5}$ & $\begin{array}{l}0.239^{*} \\
(0.135) \\
\end{array}$ & $\Delta T B_{t-4}^{+}$ & $\begin{array}{l}-0.498^{*} \\
(0.289) \\
\end{array}$ & $\Delta f f r_{t-1}^{+}$ & $\begin{array}{l}1.741^{* *} \\
(0.654) \\
\end{array}$ \\
\hline$\Delta f r_{t}^{+}$ & $\begin{array}{c}1.047 * * * \\
(0.314)\end{array}$ & $\Delta T B_{t-1}^{-}$ & $\begin{array}{l}0.951 * * \\
(0.395)\end{array}$ & $\Delta f f r_{t-2}^{+}$ & $\begin{array}{c}1.699 * * * \\
(0.607)\end{array}$ \\
\hline$\Delta f f r_{t}^{-}$ & $\begin{array}{c}0.601 * * * \\
(0.198)\end{array}$ & $\Delta T B_{t-2}^{-}$ & $\begin{array}{l}0.573 * * \\
(0.282)\end{array}$ & $\Delta f f r_{t-3}^{+}$ & $\begin{array}{l}1.092 * * \\
(0.504)\end{array}$ \\
\hline$\Delta T B_{t-1}^{-}$ & $\begin{array}{c}1.674 * * * \\
(0.589)\end{array}$ & $\Delta v i x_{t}$ & $\begin{array}{c}0.718^{* * * *} \\
(0.104)\end{array}$ & $\Delta T B_{t-1}^{+}$ & $\begin{array}{l}-1.150^{*} \\
(0.675) \\
\end{array}$ \\
\hline$\Delta T B_{t-2}^{-}$ & $\begin{array}{l}1.387 * * \\
(0.538)\end{array}$ & constant & $1.075^{* * *}$ & $\Delta T B_{t-2}^{+}$ & $\begin{array}{c}-1.444 * * \\
(0.680) \\
\end{array}$ \\
\hline$\Delta T B_{t-3}^{-}$ & $\begin{array}{c}0.902 * * \\
(0.403) \\
\end{array}$ & & & $\Delta v i x_{t}^{+}$ & $\begin{array}{c}0.952 * * * \\
(0.247) \\
\end{array}$ \\
\hline$\Delta v_{i x_{t}}$ & $\begin{array}{c}0.626^{* * * *} \\
(0.112)\end{array}$ & & & $\Delta v_{i x}^{-}$ & $\begin{array}{l}-0.678^{*} \\
(0.381)\end{array}$ \\
\hline \multirow[t]{3}{*}{ constant } & $\begin{array}{c}1.109 * * * \\
(0.402)\end{array}$ & & & $\Delta v i x_{t-3}^{-}$ & $\begin{array}{c}-0.980 * * * \\
(0.329)\end{array}$ \\
\hline & & & & $\Delta w t i_{t-2}$ & $\begin{array}{l}-0.720^{*} \\
(0.383)\end{array}$ \\
\hline & & & & constant & $\begin{array}{c}1.365 * * * \\
(0.426) \\
\end{array}$ \\
\hline$L_{\text {libor }}$ & $\begin{array}{c}0.317 \\
{[0.338]}\end{array}$ & $L_{\text {libor }}$ & $\begin{array}{l}0.657 * \\
{[0.084]}\end{array}$ & $L_{\text {libor }}$ & $\begin{array}{c}-1.804 * * * \\
{[0.000]}\end{array}$ \\
\hline$L_{f f r^{+}}$ & $\begin{array}{c}2.678 \\
{[0.153]}\end{array}$ & $L_{f f r^{+}}$ & $\begin{array}{l}-1.807 \\
{[0.299]}\end{array}$ & $L_{f f r^{+}}$ & $\begin{array}{l}-1.719 \\
{[0.397]}\end{array}$ \\
\hline$L_{f f r^{-}}$ & $\begin{array}{c}6.277 * * * \\
{[0.005]}\end{array}$ & $L_{f f r^{-}}$ & $\begin{array}{l}3.141^{*} \\
{[0.066]}\end{array}$ & $L_{f f r^{-}}$ & $\begin{array}{c}4.650 * * \\
{[0.011]}\end{array}$ \\
\hline
\end{tabular}




\begin{tabular}{|c|c|c|c|c|c|}
\hline$L_{T B^{+}}$ & $\begin{array}{c}-3.113 \\
{[0.120]}\end{array}$ & $L_{T B^{+}}$ & $\begin{array}{c}1.400 \\
{[0.455]}\end{array}$ & $L_{T B^{+}}$ & $\begin{array}{c}3.688 \\
{[0.106]}\end{array}$ \\
\hline$L_{T B^{-}}$ & $\begin{array}{c}-6.689 * * * \\
{[0.002]}\end{array}$ & $L_{T B^{-}}$ & $\begin{array}{c}-3.522 * * \\
{[0.049]}\end{array}$ & $L_{T B^{-}}$ & $\begin{array}{c}-2.581 \\
{[0.160]}\end{array}$ \\
\hline$L_{\text {vix }}$ & $\begin{array}{l}1.081 * * \\
{[0.037]}\end{array}$ & $L_{\text {vix }}$ & $\begin{array}{c}1.660^{* * * *} \\
{[0.003]}\end{array}$ & $L_{\text {vix }}$ & $\begin{array}{c}2.484 * * * \\
{[0.000]}\end{array}$ \\
\hline$L_{\text {wti }}$ & $\begin{array}{c}0.053 \\
{[0.962]}\end{array}$ & $L_{\text {wti }}$ & $\begin{array}{c}0.195 \\
{[0.860]}\end{array}$ & $L_{w t i}$ & $\begin{array}{c}0.976 \\
{[0.459]}\end{array}$ \\
\hline AIC & -67.962 & AIC & -84.439 & AIC & 26.486 \\
\hline SIC & 76.552 & SIC & 40.997 & SIC & 165.860 \\
\hline
\end{tabular}

Notes: The asterisks $* * *, * *$ and $*$ indicate significance at the $1 \%, 5 \%$ and $10 \%$, respectively.

The oil price has no long-run effect on the CDS indices, while VIX has a highly positive long-run impact on those indices, indicating that an increase or a decrease in VIX or fear in the stock market causes the CDS indices to move up as investors seek more protection against the higher volatility. It is possible that speculators who do not primarily seek protection and may not own the underlying event assets for the CDSs may also drive the CDS spreads up.

Positive changes in the federal funds rate and the Treasury bill rate have no long-run effects on the sector CDS spreads, while negative changes in the federal funds rate have a significant positive long-run effect on those spreads. On the other hand, negative changes in the Treasury bill rate have a significant negative long-run effect on the spreads. This indicates that a decrease in the federal funds rate leads to a decrease in the CDS indices, while a decrease in the Treasury bill rate leads to an increase in those indices.

The observed asymmetry is related to differences in the actions and roles played by the heterogeneous actors in the financial CDS markets which include speculators, arbitrageurs, investors and policy makers. Policy makers affect those CDS markets indirectly, while the other affects them directly. These agents have different time frames and become more active at different market and economic conditions. Speculators become more active during major credit events, while investors show enthusiasm to hold the CDSs during normal periods. 
Arbitrageurs seize opportunities when they become profitable. Policy makers through dealing with FFR in response to changes in the state of the economy affect the financial CDSs in the short- and long-run.

It is worth noting that the correction between TB and ffr amounts to 0.990. There are only minor differences in the quality of the underlying assets of those rates, and thus their rates remain very closely knitted together due to the elimination of arbitrage opportunities. Moreover, the federal funds rate can be regarded as the marginal cost of borrowing, and therefore other rates are set according to it. On the other hand, yields on long-term assets such as Treasury notes are determined in part by expectations for the federal funds rate in the future.

\subsection{Asymmetric dynamic multipliers}

Fig. 2, Fig. 3 and Fig. 4 depict the asymmetric adjustments from an initial long-run equilibrium to a new long-run equilibrium after a unit negative and positive change affecting either the 3-month Libor rate, the federal funds rate, the Treasury bill rate, VIX or WTI. The asymmetry curve shows a linear combination of the dynamic multipliers associated with positive and negative shocks. The positive change and the negative change curves indicate the adjustment paths after a positive and a negative change, respectively, in a shock at a given forecasting horizon. The lower and upper bands indicate a 95\% confidence interval for asymmetry.

The CDS_banks index reaches a new equilibrium after approximatively 5 months after a positive or a negative unitary shock to Federal Funds rate or VIX occurs, while a new equilibrium state is reached after 15 months after a positive or negative unitary shock strikes WTI. Regarding the adjustment path of the CDS_Bank index following a unitary positive or negative shock to the federal funds rate, it is shown that this unitary negative shock has a 


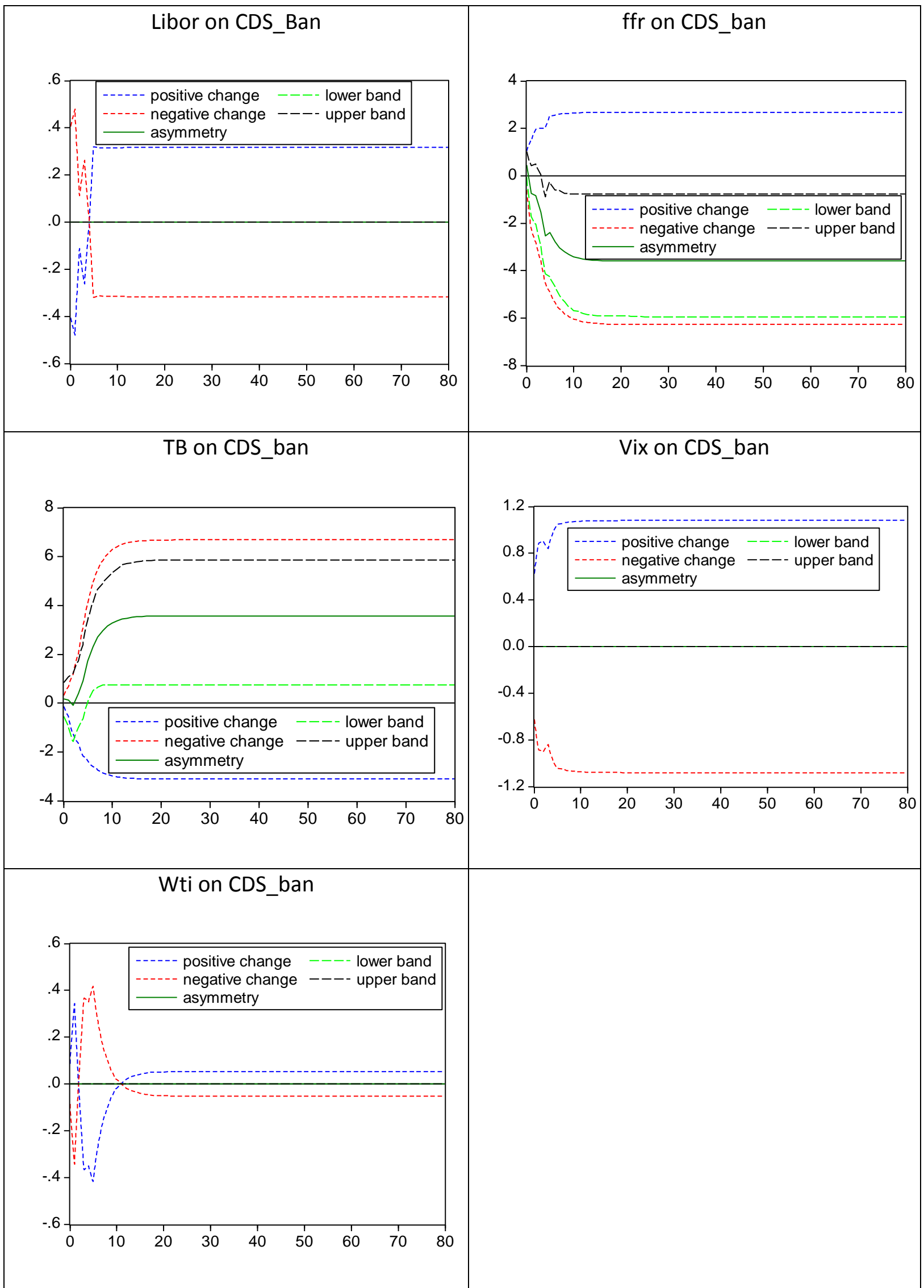

Fig. 2. Responses of CDS_Banks to shocks of control variables. In Fig. 2, Fig. 3 and Fig. 4 the X-axis represents the time horizon, while the $\mathrm{Y}$-axis reports the size of the positive/negative response of the dependent variable to a shock of each of the explanatory variables. 


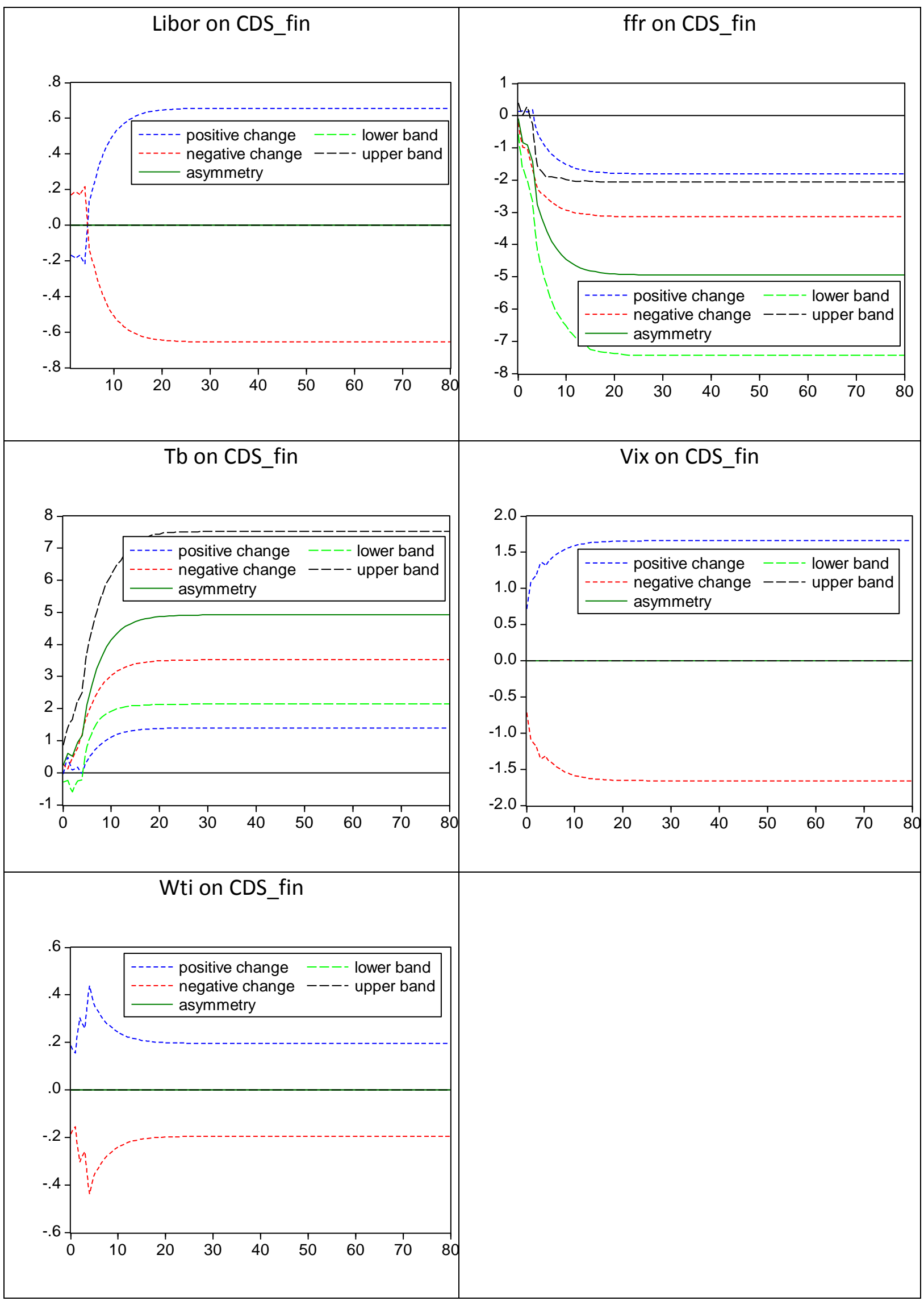

Fig. 3. Response of CDS_fin to shocks of control variables. 


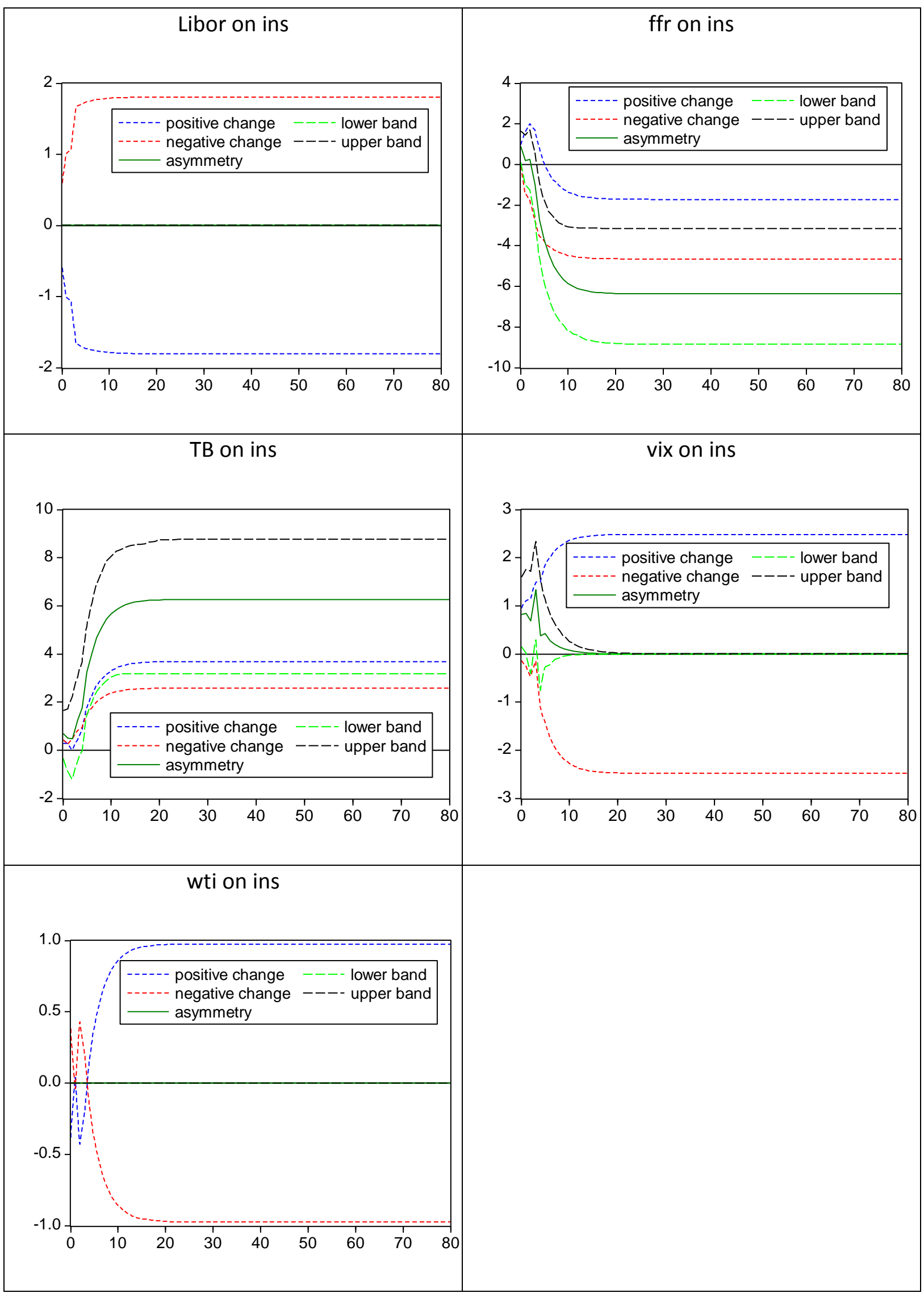

Fig. 4. Response of CDS_ins to shocks of control variables. 
stronger negative effect on the CDS_Bank index than a unitary positive shock does. The asymmetry curve is significantly negative immediately after the shock occurs. The opposite adjustment path is observed following a positive and a negative shock to the Treasury bill rate. Indeed, a positive shock to the Treasury bill rate has a negative effect, while a negative shock has a positive effect of greater magnitude. The asymmetry curve is then positive immediately after a shock to the Treasury bill occurs. The positive asymmetry is significant after almost 5 months of the shock date.

As for the reaction of financial services CDS index it reveals that unitary shocks to the 3-month Libor and the oil price imply a short-run response of the financial service CDS index that lasts approximately 10 months, then the level of the financial services CDS index stabilizes with a greater reaction to the 3-month Libor rate than to the oil price. Similar reaction of the financial services CDS index is observed after a shock to the VIX. In contrast, the financial services CDS index react in asymmetric fashion to changes in the federal funds rate and Treasury bill rate. Indeed, a unitary positive shock and a negative shock of the same magnitude to the federal funds rate render the financial service CDS index negative in the short- and long-run while similar shocks to the Treasury bill rate have an opposite effect on the financial services CDS index since the latter increases during the first ten months after the shocks occurrence and then stabilizes.

Coming to the insurance sector CDS index its reaction to the 3-month Libor rate and oil price are similar to those observed for the banking and financial services sector CDS indices. However, although asymmetric, the reaction of insurance sector CDS index to changes in the federal funds rate, Treasury bill and VIX is different from that of the banking and financial services sector CDS indices. In the short-run (5 months) insurance sector CDS index reacts insignificantly to shocks to the three above mentioned control variables. Starting from the sixth month the reaction of insurance sector CDS index is negative after a shock to 
the federal funds rate, positive after a shock to the Treasury bill rate and completely vanishes following a shock to the VIX.

Overall, results show the symmetric reaction of the three sector CDS indices spreads to shocks the 3-month Libor rate and oil price. A similar asymmetric reaction of the considered sector CDS indices spreads to shocks to the federal funds rate and the Treasury bill rate is also observed. Indeed, sector CDS spreads indices reactions are negative following a shock to the federal funds rate and positive following a shock to the Treasury bill rate. Moreover, the reaction of the banking sector and the financial services to the VIX is symmetric and significant while the reaction of the insurance sector CDS index to the VIX is insignificantly positive in the short-run and vanishes afterwards.

\section{Conclusion}

This paper examines the transmission process which links the financial variables (3-month Libor, 3-month Treasury bill rate, federal funds rate and VIX) and the energy prices (WTI) to the US sector CDS index spreads for the banking, financial services and insurance sectors over the period from January 2004 to May 2014. These variables process information on credit events and pass it on to credit risk measures. Our study period includes the recent world financial crisis which constitutes a turning point in several financial, risk and economic variables. Our approach includes the nonlinear ARDL and error correction techniques to account for short- and long-run asymmetries and nonlinearity among the variables.

The results link the short- and long-run changes in these financial sector CDS index spreads to changes in the federal funds rate and the 3-month Treasury bill rate. In terms of both the short- and long-run, these US short-term interest rates seem to figure highly in gathering information related to elevated credit risk in the United States. Positive and negative shocks to the federal funds rate and the Treasury bill rate have asymmetric impacts on the sector CDS 
indices in the short- and long-run alike. In addition, positive and negative shocks to VIX are found to be transmitted asymmetrically to the insurance sector's CDS index and symmetrically to those of the banking and financial services sectors in the short-run. However, WTI does not have any impacts on the short-run dynamics of the CDSs of the banking and financial service sectors, which are less conservative in their investments than insurance companies. The US short-term interest rates are more liquid and more sensitive to information on credit events than to WTI in the short-run. Positive and negative unitary changes in the Libor rate have the same impact on those CDS indices in the same time framework.

When it comes to the long-run, the three sector CDS indices are not sensitive to the variations in the WTI prices in the long-run. The 3-month Libor rate has a differential impact on the three sector CDS indices. It has a significant and positive long-run effect on the financial CDS index and a negative and highly significant long-run effect on the sector CDS index of the insurance companies which are less leveraged and more conservative in their investments than banks, while it has no impact on the banking sector CDS in the long-run. Banks determine Libor through a daily betting process which means there are no surprises to banks in this regard but this is not the case for the financial services and insurance companies. On the other hand, negative unitary variation of the Federal funds rate and Treasury bill rate have significant and positive long-run effect on the three sector CDS indices, probably because it signals economic downturns looming ahead. Similarly, negative shocks to the Treasury bill have a significant negative long-run effect on the banking and financial services sector CDS indices. However, positive shocks to the federal funds rate and Treasury bill rate do not have any long-run impact on those CDS indices. This shows asymmetric effects for those financial variables. VIX has a significant symmetric positive long-run effect on those indices while the latter are insensitive to variations in the oil price in the long-run. 
To sum up, the 3-month Libor, the federal funds rate, the Treasury bill rate and VIX should be regarded by investors as drivers of the sector CDS spreads. The financial sector CDS indices are thus subject to shocks from the monetary market, central banks, government and investors' sentiments. Nonlinear modeling is crucial in studying the sensitivity of sector CDS spreads indices to financial and energy variables because it allows quantifying the transmission of positive and negative shocks to those variables and trace their impact on CDS spreads. Recent studies on contagion of CDS spreads have shown that linear modeling is insufficient to capture the asymmetry and nonlinearity in the adjustment process of US sector CDS index spreads. Therefore, investors and decision makers should be aware of the source and the types of should that affects CDS spreads.

\section{References}

Arouri, M. H., Hammoudeh, S., Jawadi, F. and Khuong, D. K. (2014). Financial linkages between US sector default swaps markets. Journal of International Financial Markets, Institutions \& Money 33, 223-243.

Chen, L-H., Hammoudeh, S., Yuan, Y., 2011. Asymmetric convergence in U.S. financial credit default swap sector index markets. Quarterly Review of Economics and Finance 51(4), 408-418.

Hammoudeh, S. and Sari. R. (2011). Financial CDS, stock market and interest rates: Which determine which? North American Journal of Economics and Finance 22 (3), 257-276.

Hammoudeh, S., Bhar, R., Liu, T., 2013. Relationships between financial sectors' CDS spreads and other gauges of risk: Did the great recession change them. Financial Review 48, $151-178$

Berndt, A., Douglas, R., Duffie, D., Ferguson, M. and Schranz, D. 2008. Measuring default risk premium from default swap rates and EDFs. BIS Working Paper No. 173. EFA 2004 Maastricht Meetings Paper No. 5121.

http://www.andrew.cmu.edu/user/aberndt/Beetal08.pdf

Bharath, S. and Shumway, T. (2008). Forecasting default with the KMV-Merton Model. Journal of Financial Studies 21, 1339-1369. 
Blanco, R., Brennan, S., and Marsh, I.W. (2005). An empirical analysis of the dynamic relationship between investment-grade bonds and credit default swaps. Journal of Finance 60, $2255-2281$.

Bystrom, H. 2006. Credit default swaps and equity prices: The iTraxx CDS index market. Financial Analysts Journal 62, 65-76.

Cao, C., Yu, F., Zhong, Z.2010. The information content of option-implied volatility for credit default swap valuation. Journal of Financial Markets 13, 321-343

Chan, K. 1993. Consistency and limiting distribution of the least squares estimator of a threshold autoregressive model. Annals of Statistics 21, 520-533

Chan-Lau, J. A. and Kim, Y. S. (2004). Equity Prices, Credit Defaults Swaps, and Bond Spreads in Emerging Markets. IMF Working Papers 04/27.

Chen, X. and Kapadia, N. (2012). Understanding the Role of VIX in Explaining Movements in Credit Spreads, ......?

Che, X. and Kapadia, N.. (2012). Understanding the Role of VIX in Explaining Movements in Credit Spreads. University of Massachusetts, Amherst, MA.

Das, S. R. and Hanouna, P. 2006. Credit default swap spreads. Journal of Investment Management 4, 93-105.

Duffie, D. and Singleton, K. J. 1999. Modeling term structures of defaultable bonds. The Review of Financial Studies, 12:687-720.

Emmons, W. and Schmid, F. 2004. Monetary policy actions and the incentive to invest. Business Economics 39(2), 24-29 Also, Working Paper 2004-018A, Federal Reserve Bank of St. Louis, St. Louis, MO. https://research.stlouisfed.org/wp/view/author/64/0/1/

Ericsson, J., Jacobs, K., and Oviedo-Helfenberger, R. 2009. The determinants of credit default swap premia. Journal of Financial and Quantitative Analysis 44, 109-132.

Ericsson, J., Reneby, J., and Wang, H. 2006. Can structural models price default risk? Evidence from bond and credit derivative markets." Working Paper, McGill University. http://w4.stern.nyu.edu/salomon/docs/Credit2006/EricssonRenebyWang.pdf 
Fender, I, Hayo, B and Neuenkirch, M. (2012). Daily pricing of emerging market sovereign CDS before and during the global financial crisis. Journal of Banking and Finance 36. 27862794.

Forte, S. and Lovreta, L. 2008. Credit risk discovery in the stock and CDS markets: who, when and why leads.

http://www.efmaefm.org/OEFMAMEETINGS/EFMA\%20ANNUAL\%20MEETINGS/2008athens/Lovreta.pdf

Fung, H. G., Sierra, G. E., Yau, J., and Zhang, G. 2008. Are the U.S. stock market and credit default swap market related? Evidence from the CDX Indices Journal of Alternative Investments 11, 43-61.

Game, A. and Wu, J. (2013). A Covariate Residual-Based Cointegration Test Applied to the CDS-Bond Basis. Journal of Time Series Econometrics 5. 163-192.

Granger, C. W. J. and Yoon, G. (2002). Hidden Cointegration, University of California at San Diego, Department of Economics Working Paper Series.

Greatrex, C. 2008. The credit default swap market's determinants, efficiency and relationship to the stock market.ETD Collection for Fordham University. Paper AAI3301438. http://fordham.bepress.com/dissertations/AAI3301438

Hansen, B. E. (1992). Heteroskedastic Cointegration. Journal of Econometrics 54; 139-158.

Kucuk, U. N. 2010. Non-default component of sovereign emerging market yield spreads and its determinants: Evidence from credit default swap market. The Journal of Fixed Income.

Longstaff, F., Mithal, S., and Neis, E. 2005. Corporate yield spreads: default Risk or liquidity? New evidence from the credit Default swaps market. Journal of Finance 60, 22132253.

Nesmith, T. D. and Jones, J. B. (2008). Linear Cointegration of Nonlinear Time Series with an Application to Interest Rate Dynamics. Studies in Nonlinear Dynamics \& Econometrics $12,1-18$.

Norden, L. and Weber, M (2009). The Co-Movement of Credit Default Swap, Bond and Stock Markets: An Empirical Analysis. European Financial Management 15, 529-562. 
Norden, L and Weber, M. 2004. Informational efficiency of credit default swaps and stock market. Journal of Banking and Finance 28, 2813-2843. Also as, Discussion Paper DP 4250, Center for Economic Policy Research. London, United Kingdom.

\section{www.cepr.org/pubs/dps/DP4250.asp}

Pesaran, H. and Yongcheol Shin 1998. Generalized impulse response analysis in linear multivariate models. Economics Letters 58 17-29

Raunig, B. and Scheicher, M. (2009). Are the banks different? Evidence from CDS market. BIS https://www.bis.org/bcbs/events/cbrworkshop09/raunigscheicher.pdf

Zabel, R. R. (2008). Credit, default swaps: From protection to speculation. http://www.rkmc.com/resources/articles/credit-default-swaps-from-protection-to-speculation

Zhang, B., Zhou H. and Zhu, H. (2009). Explaining Credit Default Swap Spreads with the Equity Volatility and Jump Risks of Individual Firms. Review of Financial Studies, 22(12), pp. 5099-5131.

Zhu, H. 2006. An empirical comparison of credit spreads between the bond market and the credit default swap market. Journal of Financial Services Research 29, 211-235. 